\title{
The effect of caffeine in a nutrient medium on rhizogenesis of the Rubus genus plants
}

\author{
Svetlana A. Muratova ${ }^{1}$, Roman V. Papikhin ${ }^{1, *}$, and Yuliya V. Khoroshkova ${ }^{1}$ \\ ${ }^{1}$ Federal State Budgetary Educational Institution of Higher Education "Michurinsk State Agrarian \\ University", 393760 Michurinsk, Tambov region, Russian Federation
}

\begin{abstract}
The paper presents data on the caffeine's effect on microplants. As part of the rooting medium, caffeine can produce both positive and negative effects, depending on the concentration. The most effective range of caffeine concentrations in a nutrient medium, when plants of the Rubus genus are rooting, was determined - from 1 to $100 \mathrm{mg} / \mathrm{l}$. The use of caffeine in optimal concentration enabled the acceleration of roots growth, increase in rooting frequency, and the number of roots per rooted microcuttings. A concentration of caffeine in excess of $0.1 \%$ has a negative effect on plant tissues, slowing down and stopping the formation of roots, shoot growth and causing tissue necrosis.
\end{abstract}

\section{Introduction}

Currently, there has been a significant increase in attention to developing methods of efficient reproduction of plants in vitro. The use of the method of clonal micropropagation allows obtaining large volumes of genetically homogeneous high-quality planting material in a short time based on single initial specimens.

The in vitro microcuttings' rhizogenesis stage is the most important stage of clonal micropropagation [1]. The issues of in vitro rooting and in vivo survivability are closely related, because, as practice shows, when converting microplants to non-sterile conditions, large losses of material can be associated with weak or abnormal development of root system and underdevelopment of microplants' leaf system.

In this regard, various factors of physical and chemical nature that stimulate rhizogenesis are used. The physical factors: laser irradiation [2-4], ultrasound [5-8], light of a certain spectral composition [9].

To augment the induction of root primordia by chemical methods, including of Rubus genus plants, auxins and phenolic compounds are mainly used [1, 10-12]. Pursuit for the new root stimulants is ongoing. According to our data, caffeine can be used as a stimulator of microcuttings' rhizogenesis.

Caffeine (1,3,7-trimethylxanthine) is a compound from the group of methylxanthines that belongs to purine alkaloids and is naturally produced in almost 100 plant species [13]. Caffeine content in young leaves and seeds can be more than $2 \%$ of dry weight [14]. It is used as a psychostimulant, because it combines psychostimulating and analeptic properties.

\footnotetext{
*Corresponding author: parom10@mail.ru
} 
There is still no unequivocal opinion on the role of this substance for plants, but it can perform several important functions. Plants that produce high caffeine concentrations, such as Arabian coffee (Coffea arabica L.) and tea (Thea sinensis var. Sinensis) can use caffeine for an allelopathic effect [15].

According to J. Nathanson [16], methylxanthines (caffeine, theobromine, theophylline and other alkaloids) can negatively affect insects that feed on plants that produce these substances, and thus exhibit a pesticidal effect. This effect is due to the inhibition of phosphodiesterase activity and, at the same time, an increase in intracellular cyclic adenosine monophosphate. The pesticidal effect of alkaloids in those plant species that produce low concentrations of methylxanthines is triggered due to the strong synergistic effect of interaction with other weak pesticides [16].

According to H. Ashihara et al. [13], caffeine and its compounds are synthesized in plants under stress (tissue wounds, increased salt concentration in the nutrient medium, microbiota damage). Plants exposed to exogenous caffeine were more resistant to pathogens. For example, strains of Aspergillus ochraceus, isolated from green coffee bean and rice, were cultured on a medium containing $0.1-1.0 \%$ of caffeine. It was found that the growth of mycelium and the formation of ochratoxin A were inhibited by caffeine in concentrations above $0.1 \%$, and ochratoxin $A$ was not produced at caffeine concentrations of $0.5 \%$ and $1.0 \%$ [17].

Caffeine also directly inhibited growth of Aspergillus ochraceus in transgenic tobacco plants [18]. In addition, the antimicrobial activity of caffeine against Pseudomonas syringae is identified, which is a widespread causative agent of bacteriosis in agricultural crops [19, 20].

Another allelopathic role of caffeine is manifested in inhibiting growth of competing plants growing near producer plants [21]. In earlier studies, C. Chow and D. Waller [22] showed that water extracts of leaves, stems, and roots of Coffea arabica significantly inhibited seed germination and growth of ryegrass, lettuce, and fescue. The negative effect persisted even when the extract was diluted to $1 \%$ and it was more pronounced on young seedlings.

P. Mohanpuria, S.K. Yadav [23] studied the effect of caffeine on the development of Arabidopsis and tobacco plants. Slowing down of shoot growth was observed when plants were cultivated on MS medium containing $1 \mu \mathrm{M}$ of caffeine; increasing the concentration to $5 \mu \mathrm{M}$ significantly enhanced the effect. It was found that exposure to caffeine reduces the expression and activity of ribulose bisphosphate carboxylase in these plants. According to the authors, the observed morphological and other changes (close internodes of shoots, small root size, yellowing, decreased branching and chlorophyll content) indicate the caffeine induction of the process of early aging of plants. Thus, exogenous caffeine can affect the development of microplants in the culture of isolated tissues.

In this regard, the objective was to study the effect of various concentrations of caffeine in composition of the nutrient medium on the process of rhizogenesis of plants of the genus Rubus, which themselves do not synthesize caffeine.

\section{Materials and methods}

The biological objects of the study were the blackberry varieties Santiam, Logan Thornless and the raspberry-blackberry hybrid - Boysenberry.

Shoots of berry crops that reached a propagation medium of length $1.5-2.0 \mathrm{~cm}$ were cut and used for rooting.

At the stage of rooting of microcutting the mineral base of MS nutrient medium [24] was used with a half-reduced concentration of macrosalts with the addition of sucrose $-20 \mathrm{~g} / \mathrm{l}$, $0.5 \mathrm{mg} / \mathrm{l}$ of pyridoxine $\mathrm{HCl}, 0.5 \mathrm{mg} / \mathrm{l}$ of nicotinic acid, $0.4 \mathrm{mg} / \mathrm{l}$ of thiamine $\mathrm{HCl}, 50 \mathrm{mg} / \mathrm{l}$ of 
inositol and $8 \mathrm{~g} / \mathrm{l}$ agar. The rhizogenesis medium was without growth regulators or with 1 $\mathrm{mg} / \mathrm{l}$ of $\beta$-indolylbutyric acid (IBA) with the addition of from $0.0001 \%$ to $0.5 \%(1-5000 \mathrm{mg} / \mathrm{l})$ caffeine. The $\mathrm{pH}$ of the nutrient medium was 5.7-5.8. The medium was sterilized by autoclaving (1 atm, $20 \mathrm{~min}$ ). Vitamins, $\beta$-indolylbutyric acid and caffeine were sterilized by filtration ("Millipore" $0.22 \mu \mathrm{m}$, France) and added after autoclaving. The control experiment was on a caffeine-free medium.

Subculturing of the shoots was carried out in wide-necked conical flasks with a capacity of $250 \mathrm{ml}$ with $100 \mathrm{ml}$ of medium. The flasks were sealed with a thin aluminum foil and sealed with adhesive tape.

The plants were cultivated in a specially equipped culture room at a 16-hour daylight with 2400 lux illumination (Osram L36W Cool Daylight fluorescent lamps), air temperature of $24 \pm 2{ }^{\circ} \mathrm{C}$ and air humidity of $55-60 \%$.

The processing efficiency was evaluated after 4-6 weeks of cultivation according to the number of rooted microshoots, the number of roots formed per one rooted microplants and their length.

\section{Results and discussions}

Our data shows that inclusion of caffeine in the rooting medium can produce both positive and negative effects depending on the concentration.

Concentration of 5-100 mg/l caffeine at the rhizogenesis stage made it possible to increase the efficiency of rooting of the Logan Thornless blackberry (Fig. 1). Caffeine's effect was more pronounced on auxin-containing media. The root frequency of blackberry microcuttings increased up to $71.4 \pm 5.3 \%$ in a medium with $1 \mathrm{mg} / \mathrm{l}$ of IBA and containing 5 $\mathrm{mg} / \mathrm{l}$ of caffeine; increased up to $82.6 \pm 4.3 \%$ with a $10 \mathrm{mg} / \mathrm{l}$ concentration of caffeine in the nutrient medium; increased up to $78.3 \pm 4.5 \%$ with a caffeine concentration of $100 \mathrm{mg} / \mathrm{l}$, compared with $63.9 \pm 6.9 \%$ of the control experiment. Moreover, the dependence of the rhizogenesis indices on the caffeine concentration in the medium did not have a clear linear character.

The maximum number of roots per rooted microcutting was obtained at low caffeine concentrations. At a caffeine concentration of $1 \mathrm{mg} / \mathrm{l}$, the average number of roots per rooted microcutting was $4.9 \pm 0.4 \mathrm{pcs}$./shoot; at a caffeine concentration of $5 \mathrm{mg} / \mathrm{l}$, the average number of roots per rooted microcutting was $4.3 \pm 0.3$ pcs., compared with $3.7 \pm 0.4$ pcs. of the control experiment (Fig. 2). Stimulation of the root formation process was also obtained on Santiam blackberry. The root frequency of this variety on a medium with $1 \mathrm{mg} / \mathrm{lof}$ IBA and $10 \mathrm{mg} / \mathrm{l}$ caffeine increased to $71.3 \pm 5.0 \%$, compared to $40.1 \pm 6.8 \%$ of the control experiment; the average number of roots per rooted shoot increased up to $3.4 \pm 0.4$ pcs. at a $1 \mathrm{mg} / \mathrm{l}$ concentration of caffeine in a nutrient medium and up to $2.9 \pm 0.3$ pcs. at a $10 \mathrm{mg} / \mathrm{l}$ concentration of caffeine in a nutrient medium. In an auxin-free medium, the rooting rate of microcuttings increased up to $66.7 \pm 6.2 \%$ (the control experiment $-46.7 \pm 5.8 \%$ ) only at a caffeine concentration of $100 \mathrm{mg} / \mathrm{l}$.

Low concentration of caffeine in the medium accelerated the rhizogenesis process. The roots began to form faster, the root rudiments were established together and at the same time (Fig. 3). The roots grew faster on the hormone-free media containing 5-100 mg/l of caffeine than on the media containing auxin and caffeine simultaneously. 


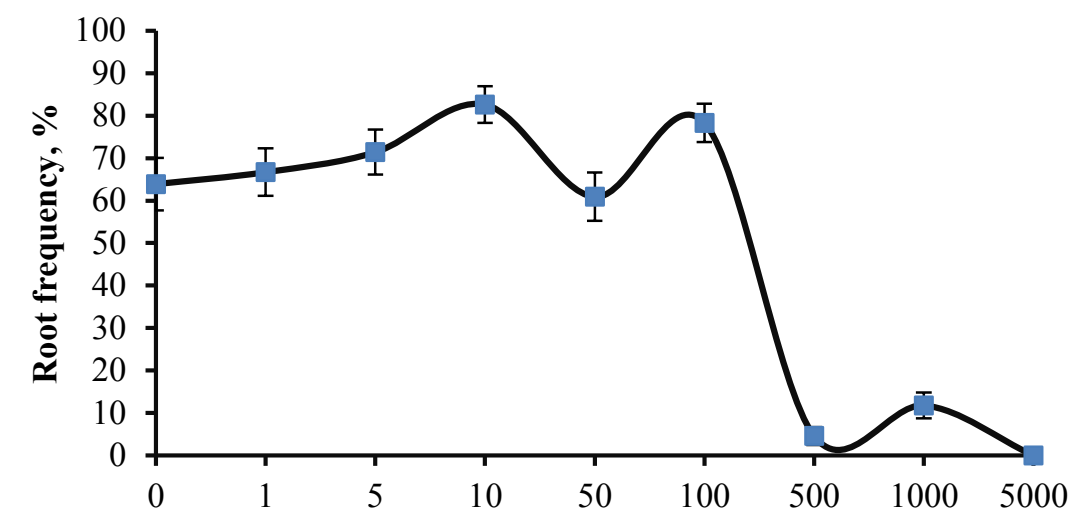

Caffeine, mg/l

Fig. 1. Efficiency of rooting of the Logan Thornless blackberry on MS medium with $1 \mathrm{mg} / \mathrm{lof}$ IBA at various concentrations of caffeine.

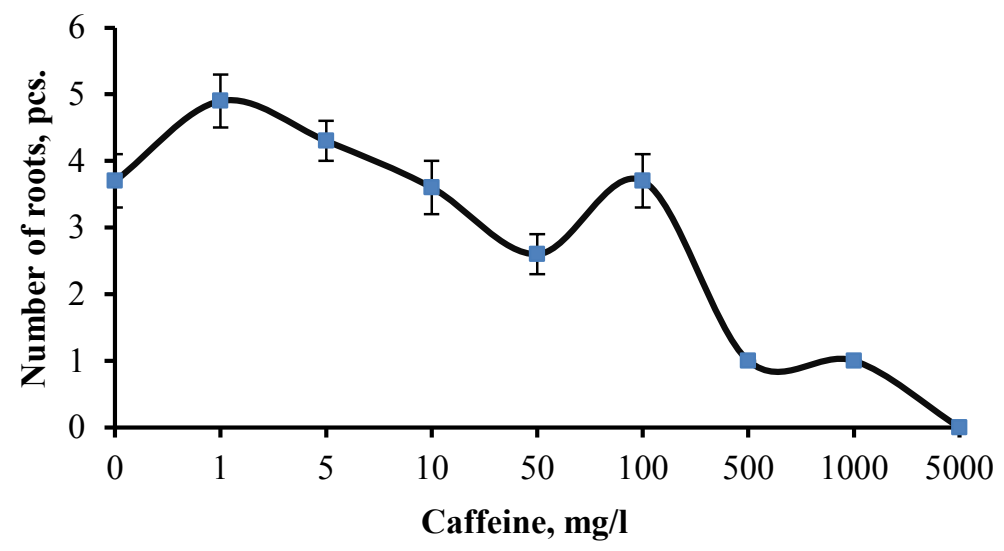

Fig. 2. Root formation of the Logan Thornless blackberry's microcuttings on MS medium with $1 \mathrm{mg} / \mathrm{l}$ of IBA at various caffeine concentrations.

Caffeine content above $100 \mathrm{mg} / \mathrm{l}$ in the nutrient medium had a negative effect on plant tissues, slowing down and stopping root formation, stopping shoot growth and causing yellowing of leaves.

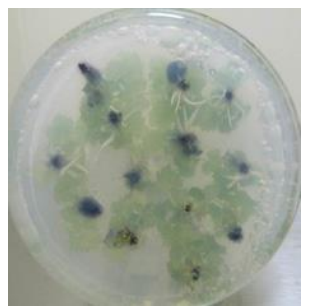

a

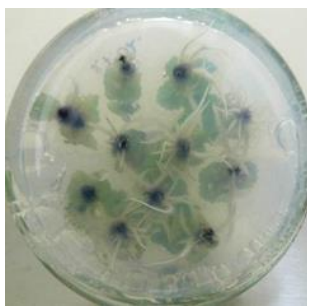

b

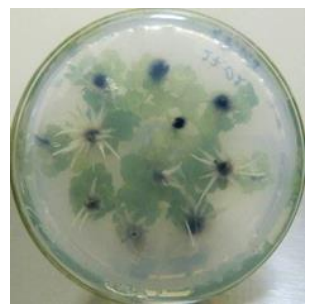

$\mathrm{c}$

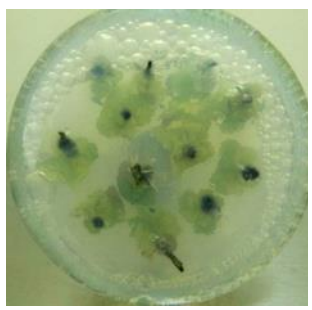

d

Fig. 3. Rhizogenesis of microcuttings of the Logan Thornless blackberry on MS medium with $1 \mathrm{mg} / \mathrm{l}$ of IBA at various concentrations of caffeine: $a$ - control without caffeine; $b-1 \mathrm{mg} / \mathrm{l}$ of caffeine; $\mathrm{c}-10$ $\mathrm{mg} / \mathrm{l}$ of caffeine; $\mathrm{d}-100 \mathrm{mg} / \mathrm{l}$ of caffeine. 
Caffeine treatment at the rhizogenesis stage allowed a 1.6-fold increase in the efficiency of rooting of the Boysenberry blackberry-raspberry hybrid. The root frequency increased to $91.7 \pm 3.3 \%$ at a caffeine concentration of $10 \mathrm{mg} / \mathrm{l}$ and up to $90.9 \pm 3.5 \%$ at a caffeine concentration of $100 \mathrm{mg} / \mathrm{l}$, compared to $56.3 \pm 6.2 \%$ in the control experiment (Fig. 4).

The average number of roots per rooted microcuttings increased from $5.9 \pm 0.3 \mathrm{pcs}$. in the control experiment; up to $7.2 \pm 0.5$ pcs. and $7.8 \pm 0.5$ pcs. at caffeine concentrations of 10 and $50 \mathrm{mg} / \mathrm{l}$, respectively (Fig. 5).

Only a few microcuttings rooted quickly and formed a significant number of roots per rooted microplant on a caffeine-free control medium, whereas root formation occurred simultaneously in multitudes on caffeinated media (Fig. 6). This led to a reduction in the duration of the rhizogenesis stage and an increase in the economic efficiency of the clonal micropropagation method.

At the same time, the presence of caffeine in the medium in high concentration was detrimental to plant tissues, causing necrosis of shoot bases immersed in the nutrient medium and yellowing of leaves, followed by partial necrosis of shoot tissues.

A similar negative effect of caffeine in certain, as a rule, high concentrations (>100 mg/l) on plant tissues under in vitro culture conditions was shown earlier by Mohanpuria and Yadav [23]. This is probably due to the natural mechanism of suppressing the vital activity of competing plant organisms and pathogenic microflora in plants that are capable of producing endogenous caffeine.

Conversely, low or trace concentrations can positively influence the morphogenetic processes. A similar effect was observed when phenolic compounds were used as rhizogenesis inducers. It was shown that phenolic compounds, depending on the chemical structure, $\mathrm{pH}$, concentration, and other factors, can act as inhibitors or as stimulators of rhizogenesis through the enzymatic system of IAA oxidation $[25,26]$.

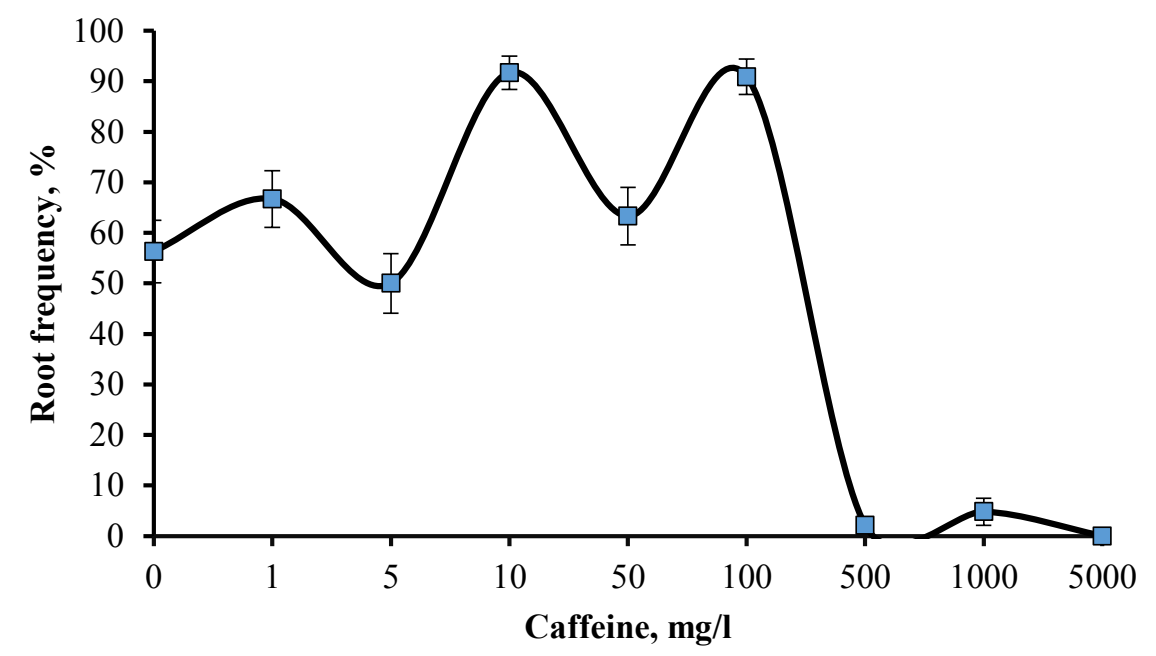

Fig. 4. Efficiency of rooting of the Boysenberry hybrid on MS medium with $1 \mathrm{mg} / \mathrm{l}$ of IBA at various concentrations of caffeine. 


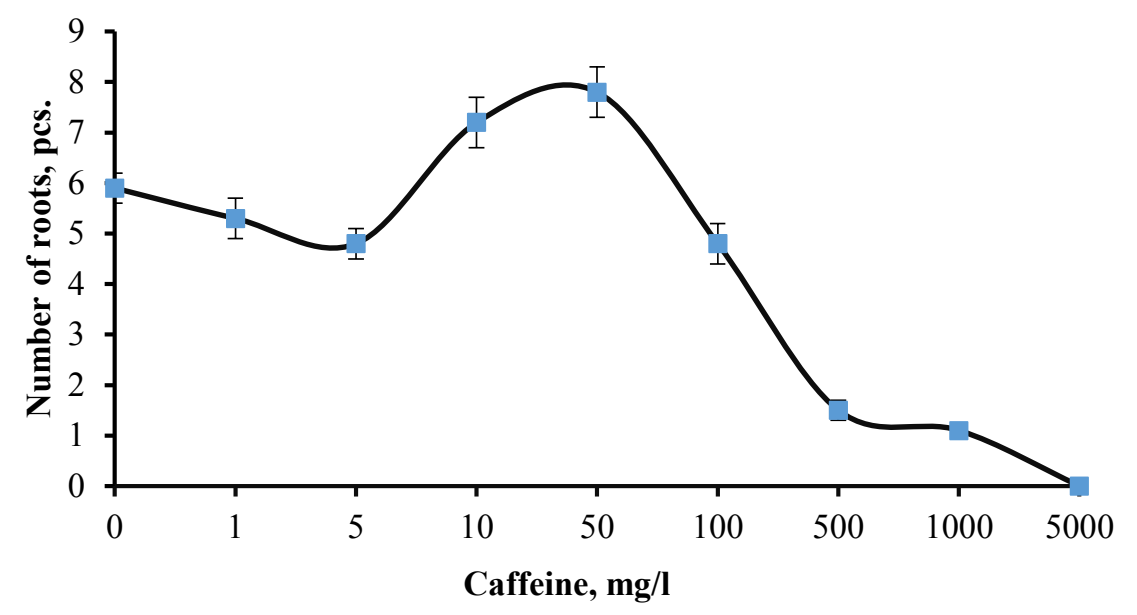

Fig. 5. Root formation of the Boysenberry hybrid's microcuttings on MS medium with $1 \mathrm{mg} / \mathrm{l}$ of IBA at various concentrations of caffeine.

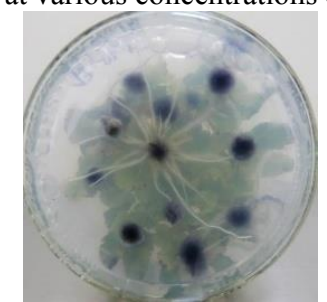

a

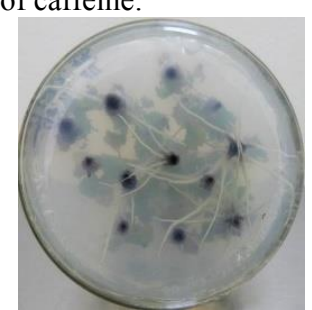

$\mathrm{b}$

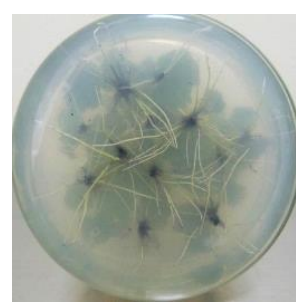

$\mathrm{c}$

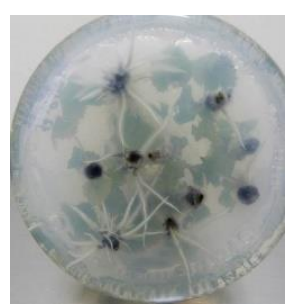

d

Fig. 6. Rhizogenesis of microcuttings of the Boysenberry hybrid on MS medium with $1 \mathrm{mg} / \mathrm{l}$ of IBA at various concentrations of caffeine: $a$ - control without caffeine; $b-5 \mathrm{mg} / \mathrm{l}$ of caffeine; $\mathrm{c}-10 \mathrm{mg} / \mathrm{l}$ of caffeine; $\mathrm{d}-50 \mathrm{mg} / \mathrm{l}$ of caffeine.

\section{Conclusion}

Our results allow us to conclude that caffeine can be used as a rhizogenesis stimulator by adding it to the rooting medium in an optimal concentration. The most effective for rooting of the genus Rubus is the range of caffeine concentrations from 1 to $100 \mathrm{mg} / \mathrm{l}$. The caffeine content in the nutrient medium of more than $0.1 \%$ had a negative effect on plant tissue, slowing down and stopping root formation, stopping shoot growth and causing tissue necrosis.

The studies were carried out in the framework of the 2020. State task of the Ministry of Agriculture of the Russian Federation on the topic: "Improving the adaptive potential of horticultural microplants by stimulating the process of rhizogenesis of microcuttings and use of biologically active substances in protected ground" on the basis of the Collective Center "Crop breeding and technologies for the production, storage and processing of food products for functional and therapeutic purposes", Michurinsk State Agrarian University.

\section{References}

1. V. I. Demenko, K. A. Shestibratov, V. G. Lebedev, Izvestiya of Timiryazev Agricultural Academy 1, 73 (2010) 
2. A. V. Budagovsky, Teoriya i praktika lazernoj obrabotki rastenij [Theory and practice of laser processing of plants] (All-Russian Scientific Research Institute of Genetics and Selection of Fruit Plants named after I.V. Michurin, Michurinsk, 2008)

3. S. A. Muratova, A. V. Budagovsky, L. A. Tokhtar, V. K. Tokhtar, L. A. Deineka, International Journal of Green Pharmacy 11, 634 (2017)

4. Yu. V. Khoroshkova, N. S. Subbotina, S. A. Muratova, Agroecological aspects of sustainable development of agribusiness: proceedings of the XV International Scientific Conference, 835 (Bryansk State Agrarian University, Bryansk, 2018)

5. R. V. Papikhin, S. A. Muratova, Horticulture and Viticulture 4, 18 (2009)

6. R.V. Papikhin, Bulletin of Michurinsk State Agrarian University 1, 38 (2014)

7. T. V. Plaksina, O. V. Mochalova, A. L. Vereshchagin, V. N. Khmelev, Polzunovsky Vestnik 4-1, 250-254 (2011)

8. A. V. Sukhorukikh, S. A. Muratova, R. V. Papikhin, Aktual'nye problemy molodezhnoj nauki [Actual problems of youth science], 226 (Michurinsk State Agrarian University, Michurinsk, 2015)

9. S. A. Muratova, N. S. Subbotina, L. A. Tokhtar, V. K. Tokhtar, V. M. Yatsenko, T. V. Petrunova, Indo american journal of pharmaceutical sciences 05, 6979 (2018)

10. M. T. Upadyshev, V. A. Vysotsky, Horticulture and Viticulture 6, 24 (1991)

11. M. T. Upadyshev, A. V. Guskov, Agricultural Biology 1, 92 (1996)

12. N. S. Subbotina, Yu. V. Khoroshkova S. A. Muratova, Nauchnye innovacii - agrarnomu proizvodstvu [Scientific innovations - to agricultural production] 933 (Omsk State Agrarian University, Omsk, 2018)

13. H. Ashihara, H. Sano, A. Crozier, Phytochemistry 69, 841 (2008). DOI: 10.1016/j.phytochem.2007.10.029

14. D. A. Smyth, J Plant Growth Regul 11, 125 (1992). DOI: 10.1007/BF00198025

15. A. L. Anaya, R. Cruz-Ortega, G. R. Waller, Front. Biosci. 11, 2354 (2006)

16. J. A. Nathanson, Science 226, 184 (1984). DOI: 10.1126/science.6207592

17. H. Tsubouchi, H. Terada, K. Yamamoto, K. Hisada, Y. Sakabe, Mycopathologia 90, 181 (1985)

18. Y. S. Kim, H. Sano, Phytochemistry 69, 882 (2008) DOI: 10.1016/j.phytochem.2007.10.021

19. M. V. Maslova, A. P. Kuznetsova, Pomiculture and small fruits culture in Russia 28, 71 (2011)

20. W. Sledz, E. Los, A. Paczek, J. Rischka, A. Motyka, S. Zoledowska, J. Piosik, E. Lojkowska, Acta Biochimica Polonica 62, 605 (2015) DOI:10.18388/abp.2015_1092

21. G. R. Waller, D. Kumari, J. Friedman, N. Friedman, C-H. Chou, The science of allelopathy, 243 (Wiley, New York, 1986)

22. C.-H. Chou, G.R. Waller, Journal of Chemical Ecology 6, 643 (1980) DOI: 10.1007/BF00987675

23. P. Mohanpuria, S. K. Yadav, Photosynthetica 47, 293 (2009). DOI:10.1007/s11099-0090045-0

24. T. Murashige, F. Skoog, Physiol. Plant. 15, 473 (1962)

25. D. G. Shornikov, M. B. Yankovskaya, S. A. Muratova, Biologiya budushchego: tradicii $i$ innovacii [Biology of the future: traditions and innovations] 82 (AMB, Yekaterinburg, 2010) 
26. M. T. Upadyshev, A. V. Guskov, Agricultural biology 5, 63 (1998) 